\title{
A importância do contexto na investigação qualitativa
}

\author{
Catarina Brandão', Jaime Emanuel Moreira Ribeiro² \\ 'Faculdade de Psicologia e de Ciências da Educação, Universidade do Porto. catarina@fpce.up.pt \\ ${ }^{2}$ Escola Superior de Saúde, Center for Innovative Care and Health Technology - CiTheCare, Politécnico de Leiria, Portugal \\ Centro de Investigação "Didática e Tecnologia na Formação de Formadores" - CIDTFF, Universidade de Aveiro, Portugal. jaime.ribeiro@ipleiria.pt
}

"la realidade é dinâmica e associada à história específica de cada indivíduo e dos contextos» (Brandão, Taquette, \& Ribeiro, 2017, p.228).

As potencialidades da abordagem qualitativa são bem conhecidas, pelo que não nos vamos debruçar sobre elas aqui. Importa, contudo, sublinhar a alavancagem empírica que oferece no ponto de vista daqueles que estão a ser estudados e a sua sensibilidade ao contexto, que se revela particularmente apelativa para investigadores numa variedade de campos (Bryman, Stephens, \& à Campo, 1996). Efectivamente, uma das principais características da investigação qualitativa é a atenção que dedica aos contextos onde decorrem os fenómenos, entendendo que os significados são criados nos contextos sociais (Neuman, 2014). Diz-se, frequentemente, por isso, que é context-sensitive. É o contexto e a sua importância que tratamos aqui.

Os contextos sociais são sistemas abertos vivos. Isso significa que são dinâmicos e que mudam, fruto da acção humana espontânea (e.g., incompatibilizar-se com alguém) ou intencional (e.g., uma tomada de decisão), assim como de even- tos não humanos (e.g., acidentes naturais). A mudança de contextos contribui de sobremaneira para os dados obtidos, pelo que quando falamos de contextos é frequentemente observável a mudança de opiniões perante flutuações contextuais de natureza temporal, espacial, socioeconómica ou outras... Como Holstein e Gubrium (2007) referem, o contexto pode entrar num jogo interpretativo de maneiras aparentemente infinitas, dado o manancial possível de perspetivas e as características contextuais inerentes não só ao contexto em si, mas também à experiência tácita do próprio investigador

O investigador qualitativo reconhece a inseparabilidade dos fenómenos do seu contexto. Esta premissa alicerça a investigação qualitativa, pois é impossivel discernir opiniões, percepções e significados dos indivíduos, silenciando o contexto. É a particularização contextualizada que permite ambicionar atingir-se níveis mais elevados de compreensão (Ribeiro, Neri de Souza, \& Costa, 2016).

Salienta-se, portanto, que a visão de um conjunto estático de circunstâncias influentes - um conjunto 
de variáveis que cercam pessoas, ações ou situações - não será a maneira mais analiticamente inteligente de interpretar o contexto. As suas múltiplas manifestações e influências variáveis sugerem que - contexto é uma constelação fluida e socialmente emergente de fatores contingentes que são "trabalhados" - não apenas encontrados - no decurso da interação cotidiana (Holstein \& Gubrium, 2007).

A importância do contexto para os processos de investigação qualitativa, na procura de lançar luz sobre um qualquer fenómeno, requer que se considere um conjunto de elementos, que vão desde o registo das características desse contexto, até à forma como se entra e sai do contexto de estudo.

De seguida debruçamo-nos sobre alguns desses elementos, reflectindo sobre os cuidados que a atenção ao contexto requerem e sobre a melhor forma de captar esse contexto, contribuindo assim para a qualidade do estudo.

\section{Entrar no contexto}

Uma vez identificado o contexto que se pretende estudar, importa que se identifiquem os procedimentos que permitem ao investigador ter acesso a esse contexto e aos seus actores ou membros. Os desafios neste acesso colocam-se particularmente quando se pretende estudar uma instituição (Flick, 1998), sendo necessário identificar os procedimentos que permitem obter a autorização de um órgão decisor com poder para tal (e.g., um conselho de administração) e dos participantes que serão entrevistados ou observados, consoante os instrumentos que o investigador decida utilizar.

Uma vez no terreno, o investigador tem de estar confortável. Isso pode passar por aprender a saber estar no novo contexto (Rodrigues, 2008), o que implica identificar as normas e os valores subjacentes aos relacionamentos nesse contexto, os comportamentos que são ou não são aceitáveis e a linguagem desse contexto. De notar que a presença do investigador no terreno e o seu contacto com os contextos estudados tem potencial para promover a mudança (Brandão, Taquette, \& Ribeiro, 2017). Importa, por isso, que $\circ$ investigador esteja vigilante sobre $\circ \mathrm{im}$ pacto da sua presença no contexto, observando em que medida é que essa presença pode impactar o fenómeno em estudo, deturpando-o. Isso pode acontecer, por exemplo, quando a presença do investigador no terreno condiciona os participantes, que alteram os seus comportamentos no sentido daquilo que consideram que será socialmente aceitável. Importa, por isso, que o investigador crie uma relação de confiança e de aceitação com os membros do contexto de estudo, minimizando o impacto que poderá ter no que se refere a uma alteração/deturpação do fenómeno e comportamento dos membros do contexto. Será porventura profícuo que o investigador seja parte do contexto que pretende investigar, assumindo-se também ele como informante-chave e dissipando a convivência com um elemento inibidor ou enviesador de comportamentos.

Alguns autores poderão, contudo, discutir se é razoável esperar que um investigador consiga manter o contexto neutro em relação à sua presença.

\section{Estudar um contexto ao qual 0 investigador pertence}

Vários investigadores discutem sobre as implicações de se estudar um contexto próximo ao investigador. Isso acontece quando o investigador estuda um grupo ao qual pertence (e.g., uma associação desportiva), a sua comunidade (e.g., cidade onde vive), ou a sua organização de trabalho. Nestas situações interessa reflectir em que medida é que o facto de se ser um ator do contexto de estudo terá influência na forma como o investigador se relaciona com os restantes membros desse contexto, nas decisões que toma ao longo do processo de investigação e na interpretação que faz dos dados recolhidos. Importa que $o$ investigador perceba se a sua postura ao longo do processo é influenciada (poderemos mesmo dizer deturpada) pela sua pertença ao contexto de estudo. Em que medida é que a interpretação de alguns dados traduzem as crenças do investigador acerca do "seu" contexto de pertença, mais do que aquilo que os participantes disseram? Em que medida é que o investigador estará a assumir premissas acerca do contexto, sem que as coloque à prova, confrontando-as ou cruzando com os dados recoIhidos? Será que alguns dados são relativizados pelo investigador quando não são coerentes com a sua leitura desse contexto ou quando colocam em causa a imagem de pessoas ou organizações importantes para $\circ$ investigador? Em que medida é 
que as crenças do investigador acerca do contexto, particularmente quando partilha características com membros desse contexto ou de um grupo particular influenciam o processo de investigação (e.g., estudar-se o processo de se tornar pai quando se luta - ou lutou - com a infertilidade)? Ao demonstrar que agiu de forma a que os seus valores ou inclinações teóricas não enviesassem a conduta da investigação e as respetivas conclusões o investigador contribui para a Confirmabilidade do estudo (Lincoln \& Guba, 2000).

Neste campo apropriamo-nos das palavras de Alarcão (2014, pp. 114-115) quando refere que $\circ$ investigador

“... não pode esquecer-se de que não é um mero participante que investiga, mas um investigador que, para o ser, assume também participar. É um investigador que participa e observa, distanciando-se para dar sentido à realidade sem a deturpar com a sua visão, embora tenha de conceder-se que, ao olhá-la, não é totalmente neutro. Mas tem de disciplinar-se para o ser tanto quanto possível. Ou então, se quiser mesmo apresentar a sua visão pessoalizada, terá de o dar a conhecer claramente aos seus leitores/ouvintes."

Note-se, ao mesmo tempo, que quando se estuda um contexto ao qual se pertence (insider research), a legitimidade e credibilidade do investigador enquanto membro desse contexto podem promover a participação dos restantes membros do contexto no estudo (Rodrigues, 2008), partilhando com o investigador as suas visões, normas de conduta e vivências. A partilha de uma mesma linguagem e de uma mesma história e cultura revela-se, assim, por vezes um facilitador da relação e, por consequência, da partilha, na medida em que os membros do contexto sentem que o investigador é "um deles" e que conhece a sua linguagem e as suas contingências. Neste caso observa-se que o sentimento de pertença a um mesmo grupo favorece a partilha. Rodrigues (2008) fala da importância de, nestes casos, o investigador "não tomar nada por garantido", no sentido em que deve evitar assumir que compreende $\circ$ que the dizem, solicitando clarificação mesmo quando (se calhar, dizemos nós, especialmente quando) possui teorias acerca das respostas e reacções dos participantes.
Todas estas questões devem ser consideradas, devendo o investigador fazer uso de estratégias que Ihe permitam auditorar o seu trabalho. Isso pode ser conseguido com o recurso a outros investigadores, que discutem $\circ$ processo de investigação, as suas opções, e a quem se submetem as conclusões, realizando uma auditoria externa ao trabalho do investigador. Os dados podem igualmente ser submetidos aos membros do contexto, que poderão posicionar-se em relação às interpretações do investigador, no processo usualmente designado por credibilidade (Lincoln \& Guba, 1991, 2000), termo paralelo à validade interna, importante para a manutenção do rigor em investigação (Coutinho, 2008).

Assim, sem que encorajemos ou desencorajemos a realização de estudos em contextos aos quais $\circ$ investigador pertença, parece-nos fundamental que se considerem as respectivas vantagens e desvantagens desse estudo, gerindo-as.

\section{Registar o contexto}

As notas de campo, largamente reconhecidas como um componente central da investigação qualitativa (Phillippi \& Lauderdale, 2018), são uma das formas de aceder à riqueza dos contextos, registando-a. Permitem ir tomando o pulso aos espaços e pessoas que ocupam e constroem um dado contexto e dar significado aos dados recolhidos. Esse registo, que deve ser contínuo, sistemático e tão rico e preciso quanto possível, revela-se fundamental para $\circ$ investigador em todas as fases do processo de investigação, desde a sua inserção no terreno, até ao momento da análise e interpretação dos dados. É ainda importante para outros investigadores, nomeadamente (mas não só) à luz do actual movimento de partilha de dados, cada vez mais defendida. Essa partilha facilita que outros investigadores possam analisar os mesmos dados, o mesmo contexto ou contextos - a confirmabilidade. Contribui ainda para se avaliar da transferibilidade dos resultados de um dado estudo (Lincoln \& Guba, 1991, 2000). Sendo verdade que alguns métodos qualitativos privilegiam o uso das notas de campo enquanto técnica chave de recolha da informação, submetendo-a a análise (e.g., etnografia), é também verdade que esta ferramenta é utilizada pela maioria dos investigadores, independemente dos seus pressupostos 
epistemológicos e métodos adoptados. As notas de campo podem incluir o registo dos primeiros passos do investigador no terreno, as suas interacções nesse terreno e observações realizadas de comportamentos verbais e não verbais, assim como as interpretações que vai formulando sobre aquilo que observa e com o qual interage.

\section{Sair do contexto}

O momento de saída ou de retirada do contexto de estudo deve também ser pensado e preparado pelo investigador. Este momento pode dar-se quando o investigador percebe que a saturação teórica (Morse, 1994) foi alcançada. Pode ainda ser definido por imperativos práticos (Rodrigues, 2008), como o caso de se ter alcançado a data de fim de um projecto.

Em alguns casos permanece a possibilidade do investigador retornar ao contexto de estudo após a retirada, seja para devolver os resultados, seja para obter validação dos mesmos. Note-se a este propósito a pertinência de se considerar o critério da Autenticidade, proposto por Lincoln e Guba (2000) e que remete, em traços gerais, para o impacto da investigação nos membros do contexto. A consideração deste critério implica que no momento em que se retira $\circ$ investigador avalie se a investigação que conduziu permitiu aos membros do contexto estudado uma melhor compreensão do seu próprio contexto (i.e., autenticidade ontológica), se permitiu que cada membro compreendesse melhor a perspectiva de outros membros (i.e., autenticidade educativa), se serviu de catalisador de mudança (i.e., autenticidade catalítica) e se deu competências aos membros do contexto estudado para agirem (i.e., autenticidade táctica). Esta reflexão é coerente com a pretensão, frequente, da investigação qualitativa em potenciar os contextos estudados, ao capacitá-los e enriquecê-los.

Nos casos em que o investigador é um membro do contexto, a retirada assume contornos particulares. Os membros do contexto têm a possibilidade de continuar a contactar mais ou menos directamente com o investigador, agora no seu papel de membro desse contexto (e.g., enquanto colega de trabalho). Essa proximidade leva a que nos momentos de in- teração possam com frequência evocar o papel de investigador, colocando-lhe perguntas sobre o estudo (Rodrigues, 2008).

A retirada do contexto pode revelar-se particularmente difícil com alguns métodos. Delamont (2007) refere o caso da etnografia, observando que alguns investigadores que operacionalizam essa metodologia por vezes resistem a abandonar o contexto, em virtude das relações que vão estabelecendo ao longo do tempo que passam no terreno (e.g., de amizade), mas também porque o trabalho de campo revela-se confortável e prazeroso.

Uma última consideração prende-se com as obrigações éticas do investigador no momento de abandonar o contexto. Essas obrigações passam por garantir que nenhum membro é prejudicado em consequência da participação no estudo, garantindo o seu anonimato e a ocultação de qualquer elemento que permita identificá-lo (a não ser que se tenha negociado o disclosure do participante), principalmente quando se estudam temas delicados (e.g., corrupção). Importa ainda garantir que os participantes mantêm uma sensação positiva acerca da sua participação no estudo.

Em jeito de conclusão, é facilmente constatável a natureza crítica e complexa dos contextos e a sua indissociabilidade da abordagem qualitativa. Emerge a sua importância contemporânea do fenómeno para uma interpretação coerente da experiência vivida individualmente e criada colectiva e socialmente. De uma forma ingénua e simplificada, pode dizer-se que o que hoje e aqui é uma verdade, amanhã e ali pode não ser, pois "mudam-se os tempos, mudam-se as vontades". Embora, muito particularmente se possa fazer uso da transferabilidade, a validade interna de um estudo qualitativo sobressai quando se dá particular atenção ao estudo e descrição dos contextos envolvidos.

Os investigadores qualitativos utilizam muitas estratégias para investigar os contextos que influem sobre a experiência. É consensual que não existe um conjunto uniforme de procedimentos de investigação. Enquanto aqueles que conduzem surveys, por exemplo, se limitam a questionários e entrevistas presenciais, os investigadores qualitativos não só 
entrevistam os seus entrevistados, como também se inspiram nas variadas maneiras pelas quais os seus assuntos se representam entre si e no espaço social.

Todavia, a aproximação e exploração de contextos reveste-se de especial atenção na relação do investigador com o contexto que investiga, procurando-se o desafiante equilíbrio entre o estar próximo o suficiente para obter uma rica e profunda interpretação, e ao mesmo tempo a distância necessária para não enviesar os resultados obtidos.

Mudam-se os tempos, mudam-se as vontades, Muda-se o ser, muda-se a confiança: Todo o mundo é composto de mudança, Tomando sempre novas qualidades. Luís Vaz de Camões, in "Sonetos"

\section{Referências}

Alarcão, I. (2014). "Dilemas" do jovem investigador. Dos "dilemas" aos problemas. In Costa, A., Neri de Souza, F., \& Neri de Souza, D. (orgs.). Investigação Qualitativa: inovação, dilemas e desafios (pp. 103124). Oliveira de Azeméis: Ludomedia.

Brandão, C., Taquette, S., \& Ribeiro, J. (2017). O Papel da Investigação Qualitativa em Psicologia? Revista Psicologia, Diversidade e Saúde, 6(4), 1022.

Recuperado de https://www5.bahiana.edu.br/ index.php/psicologia/article/view/1731/1022. doi: 10.17267/2317-3394rpds.v6i4.1731

Bryman, A., Stephens, M., \& à Campo, C. (1996). The importance of context: Qualitative research and the study of leadership. The Leadership Quarterly, 7(3), 353-370. doi: 10.1016/S1048-9843(96)90025-9

Coutinho, C. P. (2008). A qualidade da investigação educativa de natureza qualitativa: questões relativas à fidelidade e validade. Educação Unisinos, $12(1)$, 5-15. Recuperado de http://revistas.unisinos.br/index. php/educacao/article/view/5291

Delamont, S. (2007). Ethnography and Participant Observation. In C. Seale, G. Gobo, J. F. Gubrium, \& D. Silverman (Eds.). Qualitative research practice. London: Sage.

Flick, U. (1998). An introduction to qualitative research. London: Sage Publications.
Holstein, J. A., \& Gubrium, J. F. (2007). Context: working it up, down and across. In C. Seale, G. Gobo, J. F. Gubrium, \& D. Silverman. (Eds.). Qualitative research practice. (pp. 267-281). London: Sage.

Lincoln, Y. S., \& Guba, E. G. (1991). Naturalistic inquiry (Vol. 75). New York: Sage.

Lincoln, Y. S., \& Guba, E. G. (2000). Paradigmatic controversies, contradictions, and emerging confluences. In N. K. Denzin, \& Y. S. Lincoln (Eds.), Handbook of qualitative research (Cap. 6). London: Sage Publications.

Morse, J. M. (1994). Designing Funded Qualitative Research. In N.K. Denzin, \& Y. S. Lincoln (Eds.), Handbook of Qualitative research (pp. 220-235). Thousand Oaks:Sage.

Neuman, W. L. (2013). Social Research Methods: Qualitative and Quantitative Approaches (7a ed.). Harlow: Pearson Education Limited.

Phillippi, J., \& Lauderdale, J. (2018). A Guide to Field Notes for Qualitative Research: Context and Conversation. Qualitative Health Research, 28(3), 381 -388. Recuperado de http://journals.sagepub. com/doi/pdf/10.1177/1049732317697102. doi: $10.1177 / 1049732317697102$

Ribeiro, J., de Souza, D. N., \& Costa, A.P. (2016). Investigação qualitativa na área da saúde: por quê? Ciência \& Saúde Coletiva, 21 (8), 2324. Recuperado de http://www.scielo.br/pdf/csc/v2 1n8/141381 23-csc-21-08-2324.pdf. doi: 10.1590/141381232015218.15612016

Rodrigues, A. S. (2008). A definição do conceito de grupo e suas implicações no funcionamento do sistema. $\mathrm{O}$ caso das equipas cirúrgicas. (Tese de doutorado). Universidade do Porto, Porto, Portugal. Recuperado de https://repositorio-aberto.up.pt/ bitstream/10216/22788/2/29879.pdf 